\title{
Derecho a la ciudad, urbanismo unitario y vida digna: hacia la transformación de lo urbano
}

Primer semestre de 2021 - pp. 3-18 Segunda época

N.
Right to the City,

Unitary Urbanism

and Decent Life:

towards the

Transformation of

the Urban
Direito à cidade,

urbanismo unitário e

vida decente: rumo

à transformação do

urbano

Navarro Martínez, J. (2021). Derecho a la ciudad, urbanismo unitario y vida digna: hacia la transformación de lo urbano. Folios,

53. https://doi.org/10.17227/folios.53-11399

Artículo recibido $03 \cdot 03 \cdot 2020$

Artículo aprobado $08 \cdot 06 \cdot 2020$

Profesor de Historia, Geografía y Educación Cívica, Universidad Metropolitana de Ciencias de la Educación.

Correo electrónico: juan.navarro_m@umce.cl 


\title{
Resumen
}

Las desigualdades de las ciudades latinoamericanas han configurado una estructura espacial compleja desde la cual se levantan resistencias hacia el Estado y el modelo neoliberal. Tanto movimientos sociales, como intelectuales y gobiernos locales han considerado como motor de cambio el denominado derecho a la ciudad. Este artículo de tipo reflexivo tiene como objetivo plantear puentes de conexión entre Lefebvre, la Internacional Situacionista y el movimiento de pobladores chileno, con la finalidad de vislumbrar cuáles son los factores fundamentales de la ciudad capitalista y su posible transformación. Para ello, se establecerán los elementos clave de cada una de estas fuentes para finalizar con una serie de consideraciones proyectivas a tomar en cuenta. En términos generales, existe una crítica hacia el accionar jerárquico en la construcción del espacio urbano, fragmentario y alienante, en conjunto con una disputa político social del territorio. Frente a la ciudad de los expertos y tecnócratas, se encuentran los vínculos orgánicos y solidarios.

\section{Palabras clave}

derecho a la ciudad; urbanismo unitario; vida digna; espacio urbano

\begin{abstract}
The inequalities of Latin American cities have shaped a complex spatial structure from which resistance to the State and the neoliberal model are raised. Both social movements, intellectuals and local governments have considered the so-called right to the city as the engine of change. This reflexive article aims to establish bridges of connection between Lefebvre, the Situationist International and the Chilean population movement, in order to dazzle what are the fundamental factors of the capitalist city and its possible transformation. To do this, the key elements of each of these sources will be established to end with a series of projective considerations to be taken into account. In general terms, there is a critique of hierarchical actions in the construction of urban, fragmentary and alienating space, together with a social political dispute of the territory.

Facing the city of experts and technocrats, there are the organic and solidary bonds.
\end{abstract}

\section{Keywords}

right to the city; unitary urbanism; decent life; urban space

\section{Resumo}

As desigualdades das cidades latino-americanas moldaram uma estrutura espacial complexa a partir da qual se eleva a resistência ao Estado e ao modelo neoliberal. Tanto movimentos sociais, intelectuais e governos locais consideraram o chamado direito à cidade como o motor da mudança. Este artigo reflexivo visa estabelecer pontes de conexão entre Lefebvre, a Internacional Situacionista e o movimento populacional chileno, a fim de deslumbrar quais são os fatores fundamentais da cidade capitalista e sua possível transformação. Para fazer isso, os elementos principais de cada uma dessas fontes serão estabelecidos para terminar com uma série de considerações projetivas a serem levadas em consideração. Em termos gerais, há uma crítica às ações hierárquicas na construção do espaço urbano, fragmentário e alienante, juntamente com uma disputa político-social do território. Diante da cidade de especialistas e tecnocratas, existem laços orgânicos e solidários

\section{Palavras chave}

direito à cidade; urbanismo unitário; vida decente; espaço urbano 


\section{Introducción}

La cuestión urbana en la actualidad desborda un tratamiento exclusivamente académico, siendo parte del debate de políticas públicas, movimientos sociales, comunidades, pobladores, planificadores, entre otros. En un medio principalmente urbano, las ciudades latinoamericanas han sido catalogadas como reproductoras de desigualdades estructurales como lo son la segregación y fragmentación espacial.

La búsqueda de construir una ciudad menos inequitativa ha provocado tanto a nivel institucional como desde los movimientos sociales, conceptos y márgenes de acción orientados hacia dichos objetivos. Por lo tanto, un elemento central ha sido el derecho a la ciudad. Masificado con Henri Lefebvre desde su publicación El Derecho a la Ciudad en el año 1968, este concepto ha tenido una predominancia en el debate, al punto de ser integrado en políticas urbanas en los últimos años.

Sin embargo, lo anterior no ha reflejado políticas estructurales de transformaciones de las ciudades latinoamericanas, ni menos una ruptura con el neoliberalismo urbano. Algunos autores acusan de la mera cooptación del concepto vaciando su contenido radical de modificación de lo existente (Carlos, 2014). Al mismo tiempo, se han rescatado tradiciones críticas frente al urbanismo capitalista en conjunto con un auge del movimiento de pobladores en el caso chileno.

Este artículo en particular busca establecer puentes de diálogo entre tres fuentes distintas que presentan críticas al urbanismo capitalista y la ciudad desigual. El primero es el ya nombrado caso de Henri Lefebvre y el Derecho a la Ciudad, en conjunto con las retroalimentaciones de la geografía crítica. En segundo lugar, los coetáneos al anterior, los miembros de la Internacional Situacionista, quienes presentaron no solo una problematización del urbanismo como clave de reproducción del sistema de clases, sino posibilidades de su superación como el Urbanismo Unitario. Por último, desde el movimiento de pobladores, cuáles son las principales concepciones en torno a la construcción de una vida distinta y una ciudad diferente a la actual, que tome en consideración los problemas reales de las personas.

\section{Lefebvre: producción del espacio y derecho a la ciudad}

Henri Lefebvre fue uno de los principales autores que introdujo el elemento espacial a la teoría social, que influenció a los estudios geográficos y urbanos contemporáneos. Tras desvincularse de las tendencias más ortodoxas del marxismo europeo, logró evidenciar a partir de los trabajos poco estudiados o desconocidos de Marx una puesta en escena de la dimensión espacial como clave para entender la sociedad contemporánea.

Dentro de su amplia elaboración intelectual, destaca la referida a la producción del espacio (Lefebvre, 2013). El espacio se construye a partir de la base material de cada contexto en particular. Entonces, se puede afirmar que cada sociedad posee su propio espacio, el cual se encuentra sostenido en las relaciones de reproducción y relaciones de producción.

En la sociedad capitalista, en cambio, Lefebvre (2013) argumenta la existencia de tres elementos clave de la producción del espacio: reproducción de la familia, reproducción de la fuerza de trabajo y reproducción de las relaciones sociales de producción. En ese sentido, el espacio es una creación social que permite la reproducción de este y las relaciones que le crean.

Lefebvre (2013) reconoce la existencia de dimensiones de lo espacial que corresponden a tres espacios: prácticas espaciales, representaciones del espacio y espacios de representación. El primero, encontrado en el nivel más físico y directo, desde el cual los habitantes se relacionan con el entorno, es el de lo percibido de la vida material y de algunos elementos simbólicos. El segundo, se refiere a las concepciones creadas en torno al espacio. El filósofo francés lo relaciona con el espacio de los planificadores y expertos. Son las ideas abstractas impuestas a la existencia territorial, base fundamental de la mercantilización de la ciudad. 
Por último, los espacios de representación o el nivel del espacio vivido en donde existen los vínculos afectivos, pero también las posibilidades de transformación de la realidad hacia nuevos horizontes. Sigue siendo objeto de deseo, pero es el espacio de la plena existencia y vivencia que se busca y anhela.

Los tres espacios mencionados configuran el espacio social. En él, la vida en sociedad, las relaciones de reproducción y producción existen. Es una concepción unitaria de todos los aspectos que buscan una visión de totalidad que permita tanto una comprensión como un cambio en las formas espaciales existentes.

Lo urbano en Lefebvre se presenta desde distintas ópticas, como "desorden", como reunión y simultaneidad (Molano, 2016). En ese sentido, en el medio urbano existen diversas prácticas espaciales, a la vez que concepciones de organización del espacio y proyecciones de sociedades distintas.

Entonces, entendía que en el espacio urbano se concretaba una lucha de transformación desde sus mismas bases (Molano, 2016). Sin una transformación del espacio real, solamente existiría un cambio en el plano de las ideas, sin tocar la base fundamental de reproducción y producción de las relaciones sociales.

Fue durante la década de los sesenta en donde entre influencias de Marx, Engels, la sociología de la época, las luchas de los sesenta y el fin de los treinta gloriosos, o el período de reconstrucción de la posguerra, desarrolló su conceptualización del derecho a la ciudad. Este significaba de manera inicial una reapropiación de parte de clase obrera de los medios para producir la ciudad.

En la ciudad de posguerra, existe una primacía del valor de cambio sobre el valor de uso. Las ciudades perdieron su identitario dado por la cultura para pasar a ser una mercancía más, un capricho para la acumulación de capital (Lefebvre, 1969). Al mismo tiempo, como espacio fragmentado donde la vida en comunidad no es posible, la mercantilización del espacio trae consigo pérdida de sentido de la vida; de allí, que una de sus preocupaciones fundamentales haya sido encontrar en la vida cotidiana no solo las alineaciones más profundas, también la esperanza de la transformación de la sociedad.

En Lefebvre (1969) la ideología espacial en la ciudad funciona a partir de la separación del urbanismo. Por esto, su derecho a la ciudad busca una vida social integrada en el espacio. En efecto, existe una confusión entre el habitar y hábitat, reemplazado el segundo las funciones e importancia del primero.

En lo que respecta a una definición del derecho a la ciudad, además del factor de los medios de producción de ciudad, indicaba también algunos aspectos fundamentales (Lefebvre, 1969). Por un lado, el filósofo francés no planteaba regresar a un estilo de ciudad anterior. Establecía la vida urbana transformada y renovada, una teoría integral de la sociedad urbana utilizando los recursos de la ciencia y el arte; a la vez que una superación de las divisiones entre la ciudad y campo, apoyándose en los escritos de Marx y Engels. Por otro lado, otorgaba un lugar primordial a la clase obrera como agente para la realización del derecho a la ciudad a través de una estrategia que negara a la clase burguesa y su urbanismo.

Su visión sobre el derecho a la ciudad contempla la ruptura de nociones y prácticas existentes para la clase obrera. Claramente, concebir el lugar único al proletariado le significó algunas críticas que con el paso de los años fue dando a una nueva conceptualización que agregó otros grupos marginados dentro del espacio urbano como grupos étnicos, raciales, las mujeres, quienes también son agentes de disputa en torno al derecho a la ciudad.

Sin lugar a duda, la utilización del concepto del derecho a la ciudad ha permeado en las sociedades latinoamericanas ubicándose tanto de parte de movimientos sociales urbanos que le revindican como parte de su estrategia y programa, como en algunos gobiernos de izquierda que plantean, en el discurso, una gestión diferente del espacio urbano (Molano, 2016).

También, es importante de destacar su polémica con Castells (Molano, 2016). Lefebvre entendía que la lucha urbana, por la construcción de un espacio 
urbano distinto era un pilar fundamental para la construcción de una sociedad distinta. Sin embargo, para Castells, las luchas urbanas o movimientos sociales urbanos solo propondrían reformas al espacio urbano, no una proyección hacia el fin del sistema capitalista. En ese sentido, las demandas urbanas eran peticionistas y formaban parte de un conflicto mayor en contra del capital.

\section{Aportes desde la geografía crítica sobre el derecho a la ciudad}

Sin lugar a duda, la obra de Lefebvre impulsó a variados autores de las ciencias sociales, sus planteamientos sobre el espacio para entender la estructura social, la importancia de la vida cotidiana, sus aportaciones de un marxismo dialéctico heterodoxo o el ya mencionado derecho a la ciudad siguen vigentes hasta nuestros días. Proponemos hacer una revisión sobre cuatro autores: David Harvey (1990; 2004; 2013), Edward Soja (1996; 2008) de parte del mundo anglosajón, en conjunto con Milton Santos $(1996 ; 2007 ; 2009)$ y Ana Fani Alessandri Carlos $(2014 ; 2015)$ del pensamiento geográfico latinoamericano.

David Harvey (1990), ha dedicado gran parte de su trabajo académico de las últimas décadas a tratar de caracterizar la dimensión espacial del capitalismo que argumenta se encontraba implícita en Marx, y que provocó una primacía de la dimensión temporal dejando de lado el espacio. Sus esfuerzos han caracterizado tanto maneras de expansión de la acumulación como las resistencias.

Uno de sus aportes medulares se refiere al mecanismo denominado ajustes espacios temporales, forma en que el capital logra hacer frente a las crisis de sobreacumulación, por medio de la ampliación de las fronteras productivas y apertura de mercados (Harvey, 1990). Posteriormente, lo relacionaría con la acumulación por desposesión con la cual los gobiernos neoliberales han privatizado servicios sociales esenciales que afectan una gran parte de la población, al mismo tiempo, que un nuevo periodo de depredación de zonas naturales antes ajenas a los procesos productivos (Harvey, 2004).
En ese sentido, el derecho a la ciudad es parte de su repertorio conceptual. Sin embargo, plantea una diferencia importante con Lefebvre. Para Harvey (2013), las disputas urbanas frente al capitalismo son un momento dentro de una lucha anticapitalista más amplia. Lo anterior, anclado en una noción de transformación de la sociedad que considere una reconfiguración hacia la totalidad del espacio su producción y reproducción.

En la actualidad, la acumulación flexible ha sido aplicada a la ciudad. El Estado pierde capacidad de control al ser un facilitador entre privados y entes financieros que actúan directamente (Harvey, 2010). Entonces, la economía urbana se fundamenta en ventajas comparativas de las ciudades para atraer la inversión extranjera. La primacía del bien de cambio por el bien de consumo trae como consecuencia la destrucción de la ciudad como bien social.

Como consecuencia de lo anterior, Harvey (2010) plantea el derecho a la ciudad frente a la hegemonía del capital como a manera de estación de paso frente a la transformación total de la sociedad. Sin lugar a duda, es una acumulación de experiencias, un reencuentro de habitantes que resisten; mas estas demandas no siempre se consideran dentro de un horizonte socialista y anticapitalista, que conllevaría a una reconfiguración profunda de los asentamientos humanos tanto urbanos como rurales.

Edward Soja es otro autor que ha tomado gran parte de la obra de Lefebvre, profundizando algunos de sus aspectos y complementando sus teorías. Pese a ser considerado como posmoderno, no ha dejado nunca de lado una visión de transformación de la sociedad y un conocimiento situado desde las luchas sociales propio de la geografía radical del siglo $\mathrm{xx}$.

En primer lugar, Soja (2008) entiende que el espacio urbano debe ser abordado de tantas aristas como en él se encuentra diferentes desigualdades y marginalidades provenientes de diversas fuentes como lo son: la clase, el género, la cultura o la raza. Desde esa línea establece que los elementos culturales en la construcción de la ciudad son fundamentales para vislumbrar sus configuraciones en la actualidad. 
Soja (1996) tomó como referencia los tres espacios de Lefebvre correspondientes al espacio percibido, espacio concebido y espacio vivido como elementales en la construcción de la sociedad. Para él, el primer espacio corresponde a la vida material; el segundo, a las representaciones mentales; el tercero, a una mezcla producida por los dos anteriores que permite comprender la multiplicidad de formas de habitar la ciudad.

En otro sentido, reconoce un dualismo en la ciudad: normalización versus subversión. De esta manera, el espacio urbano se encuentra atravesado por oposiciones y contradicciones donde se articulan las alternativas para superar el estado actual de las cosas (Soja, 2008). Al mismo tiempo, intenta romper con el binarismo propio del pensamiento moderno al utilizar los tres espacios como forma de aproximación a la realidad espacial, en la búsqueda de justicia espacial en las áreas hibridas o zonas fronterizas (Soja, 1996).

Sus estudios de la ciudad de Los Ángeles, que pasaron por su fase de desindustrialización y conversión a ciudad de entretenimiento y producción cinematográfica, le permitieron definir una serie de paradojas de la posmetrópolis (Soja, 2008). En estas, se encuentran procesos de desindustrialización y reindustrialización, de descentralización y centralización, de construcción de espacio público y de seguridad de un archipiélago carcelario. Todo bajo una serie de combinaciones a partir de una hegemonía global que no deja de lado las características propias de cada posmetrópolis que la hacen ser multidimensional y cambiante.

Como reflexión en torno a las luchas urbanas y el derecho a la ciudad, Soja entiende que las injusticias que se encuentran en el espacio urbano están atravesadas tanto por desigualdades económicas como extraeconómicas. Sin una comprensión ampliada de aquellas es imposible lograr alternativas.

A diferencia de Harvey, Soja (2008) propone que el derecho a la ciudad es una zona de encuentro de diferentes luchas urbanas que posee un horizonte de posibilidades inmediatas de cambio. Lo anterior se fortalece en un contexto de atomización y pérdida de lazos sociales en un espacio urbano dominado por la apatía y el individualismo neoliberal. La mera lucha contra el capitalismo deja de lado otras geografías de la desigualdad que al articularse pueden disputar formas de gobierno local o regional en una línea que busque mayor justicia y democracia.

En Latinoamérica, el aporte de Milton Santos a la geografía es incomparable. Ningún otro autor de raíces marxistas logró impactar de tal manera a la geografía crítica como lo ha hecho él. Enfocado principalmente en la técnica y en el espacio, Santos trabajó temáticas variadas, siempre centrado en los efectos de la globalización y en las asimetrías espaciales.

Santos (2007) propone la relación entre formaciones sociales y el espacio, poseen una materialidad propia de una estructura técnica y productiva histórica. Por lo tanto, existe un diálogo entre formas espaciales, funciones y estructuras donde se establece una combinación entre elementos globales y locales.

Para Santos (1996), la globalización impacta en la ciudad utilizando como un punto de una red mayor de búsqueda de nuevas regiones de inversión provocando una complejidad en la división internacional del trabajo. La actualidad marcada por un contexto de desarrollo de la técnica y la información convierte al espacio urbano en algo más que una posibilidad de acumular excedentes, sino en la capacidad del sistema financiero global de buscar nuevos espacios y conectarlos siempre desde la verticalidad que le caracteriza.

Su propuesta de una economía política de la urbanización busca desentramar la acción de agentes globalizadores, la nueva división del trabajo, el poder, el control, valorización del espacio urbano, así como la contrahegemonía que intenta resistir a la verticalidad impuesta (Santos, 2009). Por ello, su conexión con el derecho a la ciudad integra la dimensión de una globalización latente, la acción en red, siempre considerando las formaciones sociales y espaciales propias del capitalismo periférico latinoamericano.

Para la geógrafa brasileña Ana Fani Alessandri Carlos, el espacio urbano se encuentra bajo una contradicción fundamental. Por una parte, el proceso de 
producción social del espacio y por otra, la apropiación privada de este. Esta tensión provoca segregación y marginación a partir de la imposición de la mercantilización en el medio urbano.

La abstracción aplicada al espacio y la vida cotidiana crea desigualdades. El desarrollo de la técnica produce una urbanidad artificial propia de un consumidor (Carlos, 2014). Como consecuencia de estos fenómenos, la producción de ciudad se concibe como una exterioridad ajena a sus habitantes.

Para Carlos (2014) la tensión fundamental en el espacio actual es la disputa del espacio público al capital financiero y la autonomía política del derecho a la ciudad. En el primer caso, en un contexto neoliberal donde el capital financiero invierte y obtiene rentas en la medida que el espacio público se privatiza, fragmenta y aliena. En el segundo caso, como una crítica a la utilización a modo de cooptación de la capacidad transformadora del derecho a la ciudad.

Para continuar con aquella reflexión, Carlos (2015) plantea las limitaciones de un derecho a la ciudad que no considere las raíces marxistas desde la cual Lefebvre propuso originalmente el concepto. En efecto, un derecho a la ciudad como mero derecho social asistencial no considera la profunda crítica al Estado y el capital que el autor francés planteó en su contexto. De esta forma, en la actualidad latinoamericana, pese a existir gobiernos de izquierdas proclives al derecho a la ciudad se deja de lado la acción del capital financiero y las políticas urbanas que no rompen con la separación entre expertos y habitantes.

Al mismo tiempo, utilizando como ejemplo el caso de Sao Paulo, considera que las políticas urbanas progresistas, pese a tener intenciones de satisfacer la demanda habitacional, mantienen una funcionalidad subsidiaria de parte del Estado hacia las empresas privadas, sin tocar el fondo de la acumulación de capital a partir del mercado inmobiliario (Carlos, 2014).

La ciudad neoliberal contrapone el tiempo del capital financiero al tiempo de la vida cotidiana y de la comunidad (Carlos, 2014). Uno de los aspectos fundamentales de las luchas urbanas es lograr subvertir la vivencia del tiempo controlada desde los fines acumulativos. En ese sentido, Carlos plantea que se ha producido una especulación de las fiestas trasladándose su foco a una dimensión privada, lo que trajo como consecuencia una pérdida del sentido del espacio público.

\section{Internacional Situacionista: ideología, fragmentación y urbanismo unitario}

La Internacional Situacionista fue un grupo existente en Francia que propuso la superación del arte y de la sociedad capitalista mediante el uso de diversas herramientas que lo permitieran, de allí las situaciones que le otorgan su nombre (Jappe, 1998). El arte se basa en una separación fundamental entre la obra y el espectador que posee un rol pasivo, de esa forma como mero gozador de una mercancía, su superación necesita el término de dicha funcionalidad.

Dentro de sus preocupaciones, destacaron elementos relacionados a la cultura, el comportamiento humano, la sociedad de posguerra y los temas urbanos. El espacio urbano en el situacionismo es duramente criticado por ser servil a la dominación capitalista (Internacional Situacionista, 2001). Razón por la cual es un elemento fundamental en la separación de la vida en distintas esferas.

La ciudad bajo la sociedad posindustrial privilegia la circulación (Debord, 2001a). Pero no cualquier circulación, el espacio urbano está diseñado y reproducido para la circulación de vehículos. Entonces, la obtención de un automóvil es percibido para las familias como un estatus social, sinónimo de progreso y desarrollo. Un entorno construido solamente para el movimiento de máquinas imposibilita el tránsito desenvuelto de las personas, a la vez que construye una realidad en donde las cosas se sobreponen a las personas.

La reproducción del medio urbano a escala mundial y la aglomeración provocan una banalización (Internacional Situacionista, 2001). De esa manera, la rutina se transforma en elemento fundante de la vida de quienes viven en las grandes ciudades (Constant, 2001). Si existe una necesidad que no sea directamente obtener el sustento en la sociedad europea, en donde se sitúa la Internacional Situacionista, es 
no morir de aburrimiento (Vaneigem, 2001). La pseudo colectividad producto de la acumulación de habitantes nace desde los vínculos artificiales que la vida moderna impone. La comunidad desaparece en donde los lazos se basan en la mera reproducción del valor de cambio.

El urbanismo no es más que la continuación ideológica en el sentido de Marx (Kotanyi y Vaneigem, 2006). El concepto de ideología para Marx es fundamental, no solo para entender su propia obra, sino para comprender la preocupación de la Internacional Situacionista de superar el urbanismo.

La ideología es la manera en que las sociedades separadas en clases logran reproducir el orden del mundo que la dominación del medio material les permite (Marx y Engels, 1974). El mundo presentado de manera inversa es una metáfora a la capacidad, principalmente de la burguesía, de establecer que el mundo en el que nos desenvolvemos ha sido de esta manera desde siempre, negando su calidad histórica.

En la ideología alemana, Marx y Engels (1974) rompen con la concepción hegeliana de una esencia de las cosas ancladas en la "idea". Para ambos, son las condiciones materiales históricas las que construyen determinadas ideas. La conciencia, entonces, no es un mero reflejo de los objetos, resulta como producto de relaciones sociales en un contexto.

La clase dominante construye ideología en la medida de que sus propios intereses son validados como universales mediante el control de la producción mental (Marx y Engels, 1974). Nociones como libertad e igualdad se presentan como ideales propios de la sociedad; sin embargo, están reservados para el área de la economía, la cual en Marx existe dominando al resto y son conjeturas para el común de las personas.

Entender el urbanismo como ideología es concebirlo como separación (Debord, 2001). En efecto, quienes habitan la ciudad no tienen la capacidad ni el conocimiento para comprender el medio en donde se desenvuelven, no obstante, existen en él (Internacional Situacionista, 2001; Kotanyi y Vaneigem, 2006). La ciudad es mostrada como la forma de existencia actual, sin considerar su construcción histórica, las relaciones sociales que la producen, sus contradicciones y su funcionalidad en la acumulación de capital.

La función de los planificadores, de los urbanistas, se encuentra alejada de la vida cotidiana y de la calle, por lo que construyen un espacio abstracto que se impone (Debord, 2000; Ivain, 2006). Por ello, el situacionismo reivindica la psicogeografía y la deriva (Debord, 2001b). La primera, como el enfoque en donde las emociones que los espacios provocan en las personas desde una perspectiva fenomenológica. La segunda, como una actitud de resignificación de los espacios urbanos al romper con los desplazamientos planificados, buscando nuevas sensaciones y experiencias.

Con el ánimo de criticar la funcionalidad del urbanismo desde las autoridades y expertos, la Internacional Situacionista establece que sus decisiones provocan un condicionamiento (Kotanyi y Vaneigem, 2006). La ciudad se diseña para la acumulación de capital y aislamiento de sus sujetos; en términos de lazos orgánicos, el condicionamiento es a partir de seguir una pauta de vida preestablecida donde el trabajo es una función fundamental.

Desde esa visión, la crítica a la circulación ya mencionada toma más sentido al construirse carreteras y priorizarse la movilización en vehículos unifamiliares (Debord, 2001a). La circulación permitida no corresponde a las personas, más bien a mercancías. El error está en considerar al automóvil como el centro de la construcción de la ciudad. Es allí donde la definición de espacios de trabajo y espacios de alojamiento debe romperse para una nueva arquitectura que privilegia un nuevo criterio: espacios para la vida.

Entonces, las nociones de espectáculo y urbanismo se entrelazan. El espectáculo es una categoría con que Debord (1994) analiza las sociedades posindustriales. En efecto, la existencia actual se encuentra mediada por imágenes. Siguiendo las nociones de ideología de Marx, Debord establece que la sociedad consume imágenes de ciertas funciones de la vida, creyendo que estas son reales. 
Aplicado el espectáculo al urbanismo, el resultado es la imagen de la supuesta participación y construcción democrática de las ciudades cuya consecuencia es la imposición de las necesidades de acumulación de capital, del espacio de los técnicos y planificadores, de la supresión del encuentro.

En contraposición con el urbanismo a secas, los miembros de la Internacional Situacionista presentaron el concepto del Urbanismo Unitario (Ivain, 2006; Kotanyi y Vaneigem, 2006). Esta propuesta buscó romper con la separación de la esfera del urbanismo tradicional con la sociedad que vive en el espacio urbano. De esa forma, serían los mismos habitantes quienes construirían el medio o los ambientes en donde se desenvolvieran.

El urbanismo unitario se concibe como crítica y práctica a la vez: "Crítica viviente quiere decir establecimiento de las bases para una vida experimental: reunión de creadores de su propia vida en terrenos equipados para sus fines" (Kotanyi y Vaneigem, 2006, p. 26) En consecuencia, no se propone construir espacios separados bajo el prisma actual de espacios dormitorio, espacios de trabajo, más bien espacios que consideren todos los aspectos de la vida, teniendo como enfoque ineludible la satisfacción de todas las necesidades y el goce.

Para que el urbanismo unitario funcione, requiere de la creación permanente de signos que pertenezcan a todos. Es decir, un nuevo lenguaje y acción espacial que sea capaz de involucrar las necesidades y deseos de quienes habitan el espacio urbano.

\section{Movimiento de pobladores, hacia la vida digna}

El movimiento de pobladores ha sido un tema recurrente en las ciencias sociales en Chile como un movimiento social multiforme ligado a las demandas habitacionales junto con otras reivindicaciones, aunque esta es la que le da su propia identidad (Herrera, 2018). Sus primeros rastros se encuentran en las movilizaciones de los años veinte en torno al alza de los arriendos en la ciudad de Santiago, y se mantiene hasta nuestros días en un contexto de nuevas demandas de construcción de la ciudad.
En términos generales, la literatura ha reconocido tres grandes periodos de desarrollo histórico del movimiento de pobladores (Herrera, 2018; Angelcos, 2012). Un primer momento, se encuentra desde la década de los años cincuenta hasta el golpe militar, caracterizado por las tomas y autoconstrucción como mecanismo de solución a la necesidad de vivienda. Un segundo momento, durante las protestas de los ochenta en contra de la dictadura militar de Augusto Pinochet. Un tercer momento, desde los noventa hasta la actualidad, considerando los cambios introducidos por el neoliberalismo, nuevos repertorios de acción y reivindicaciones urbanas.

A mitad del siglo $\mathrm{xx}$ la sociedad chilena se encontraba en pleno auge del éxodo campo ciudad. En efecto, el espacio urbano ofrecía ciertas características que resultaron atrayentes, tales como la incipiente industrialización o la disponibilidad de vivienda, en conjunto con un decrecimiento del sector rural. Como consecuencia, la vivienda existente fue copada rápidamente quedando como opción la autoconstrucción ante la creciente demanda (Herrera, 2018).

El habitar espontáneo de la periferia urbana del Santiago de aquellos años fue dando forma a lo que se conoció como las poblaciones callampas (Herrera, 2018; Movimiento de Pobladores en Lucha, 2011). Caracterizadas por sus materiales ligeros y la falta de infraestructura, comenzaron a ser una temática recurrente para la clase política preocupada más por la posibilidad de que estos sectores resultaran problemáticos para el orden público, que por dar solución a sus demandas.

Este nuevo habitar fue estableciendo una verdadera frontera en la ciudad. El zanjón de la aguada se transformó en la frontera entre la civilización y la barbarie (Cortés, 2014). De esa manera, hacia el sur del área urbana consolidada de la ciudad se comenzaron a ubicar diversos campamentos con una variable planificación tanto en la toma de terrenos como en la organización interna. Este sector fue denominado el cordón de la miseria.

Una de estas ocupaciones, considerada como el hito que da nacimiento al movimiento de pobladores, 
fue la toma de la Victoria el día 30 de octubre de 1957, en la que un grupo de pobladores hizo ocupación de los terrenos de la chacra la Feria (Cortés, 2014). La acción colectiva demostró un altísimo nivel de organización, lo que conllevó más que a la defensa de la toma. Significó una planificación y trazados de calles. Por primera vez, los pobladores eran protagonistas y los propios urbanistas. Se lotearon los espacios de vivienda, se nombraron calles, idearon espacios comunes, se instaló el tendido eléctrico y cañerías.

Este nuevo actor que irrumpía en el espacio urbano quebró los esquemas tradicionales de una izquierda que consideraba que las transformaciones se encontraban en la fábrica y los sindicatos (Herrera, 2018). La toma de la Victoria significó una inspiración en un ciclo de acciones colectivas que irían en aumento hasta el gobierno de la Unidad Popular.

Para algunos autores, la dictadura militar significó una pérdida de identidad y motivaciones dentro del movimiento de pobladores. El accionar colectivo que caracterizó la fase anterior se transformó en una resistencia en formas de protestas en las poblaciones urbanas durante las jornadas de paro nacional de la década de los ochenta. En efecto, la crisis económica que azotó al país a comienzos de los ochenta trajo consigo desempleo y encarecimiento de los productos básicos con los que las ollas comunes y la organización comunitaria fueron mecanismos de sobrevivencia y resistencia, tanto para la represión como para la dura situación.

La tercera fase se inició una vez terminada la dictadura militar, mediante un pacto de la oligarquía chilena, en donde se inicia un nuevo proceso en el movimiento de pobladores. Es necesario recordar que la década de los noventa se caracterizó en materia urbana por intentar dar solución al déficit habitacional de cerca de 500000 viviendas. La producción en masa de vivienda social durante los primeros gobiernos de la Concertación configuró espacialmente una periferia marginal en donde existía aún suelo disponible a bajo costo. $\mathrm{Al}$ mismo tiempo, emergió la figura del comité de vivienda como forma organizativa que reemplazó el accionar de las tomas y la autoconstrucción.
Pese a los intentos de aquellos gobiernos, la producción masiva de vivienda dejó de lado algunos aspectos esenciales como la calidad de estas, la conectividad o la presencia de servicios asociados (Movimiento de Pobladores en Lucha, 2011). Durante los primeros años, los pobladores fueron abandonados en zonas con difícil acceso, pasando duros inviernos donde estas construcciones no lograron resistir los lluviosos fines de los noventa.

Posterior al terremoto de 2010, la literatura referente al movimiento de pobladores encuentra una crisis de la vivienda neoliberal y una nueva aparición de este (Herrera, 2018; Angelcos 2014). El modelo imperante de subsidio al privado había encontrado su límite en la imposibilidad de los sectores más marginales de la sociedad de acceder a la vivienda, al mismo tiempo que una exorbitante elevación del precio del suelo.

En el caso específico de la comuna de Peñalolén, la disponibilidad de suelo y la larga trayectoria de la autoconstrucción provocó que fuera un espacio de gran movilización desde finales de los noventa a comienzos del nuevo siglo. La toma de Peñalolén, como fue denominada, trajo consigo una disputa de parte de población allegada que vivía en la comuna que reivindicaba la posibilidad de seguir formando parte del territorio que habitaban (Movimiento de Pobladores en Lucha, 2011). Pese a la represión, los intentos de los sectores acomodados de la comuna y la política urbana centralizada lograron ir ganando terreno en la administración local generando nuevos espacios de territorialización y tejido orgánico.

De estas experiencias surgió el Movimiento de Pobladores en Lucha (MPL) (2011). Esta organización se considera una agrupación que busca disputar y establecer alternativas a la urbanización neoliberal imperante en el contexto chileno. El MPL se plantea desde la autogestión y autoorganización de los grupos marginados que han visto imposibilitados el acceso a la vivienda, así como vulnerados el cumplimiento de otros derechos, como salud física y mental, educación, bienestar laboral, igualdad de género, etc. 
Bajo la política subsidiara habitacional que caracteriza a las ciudades chilenas, la legislación emanada desde el Ministerio de Vivienda creó la figura de las Entidades de Gestión Inmobiliaria Social (EGIS), encargadas del asesoramiento y acompañamiento de quienes desean obtener subsidios para la construcción de viviendas.

Por ello, al proponerse desde el Estado que sean entidades privadas alejadas de la realidad de los y las pobladores que el MPL (2011) propuso una estrategia de levantar su propia EGIS o Entidades de AutoGestión Inmobiliaria Social y su propia constructora, con la finalidad de disputar todo el proceso de construcción de la vivienda, desde su planificación, la postulación a subsidios, el diseño, su ejecución y entrega.

Uno de los elementos centrales que aporta el MPL (2011) como saber emergido desde la experiencia de lucha es que la mera reivindicación habitacional reproduce desigualdades y la dominación paternalista de parte de los gobiernos de turno. Es la política de migajas y soluciones de tipo "parche" que tienen como objetivo evitar una consolidación del proceso autoorganizativo de los pobladores la limitante de solamente centrarse en la búsqueda de la vivienda. De esa manera, es una crítica a la política habitacional de los noventa.

Desde otro ángulo, la política subsidiaria es vista como un mecanismo que continúa marginando a la población más precarizada y conlleva que sea el privado quien tome todos los beneficios (Movimiento de Pobladores en Lucha, 2011). La falta de una política real habitacional hacia el movimiento de pobladores crea la necesidad de que sean estos actores quienes tomen el proceso completo de producción de vivienda y entorno.

En el sentido que se plantean desde el concepto de la vida digna, que posee sus bases filosóficas en los pueblos originarios americanos, consideran que las condiciones de una existencia plena para los pobres de la ciudad no es un lugar específico donde llegar, o una demanda a la cual el Estado deba satisfacer. Se presenta como horizonte de lucha y movilización con el fin de alcanzar la dignidad que todos los pueblos merecen.
La otra fuente de la perspectiva del movimiento de pobladores que consideraremos es la proveniente de Ukamau (Herrera, 2017). Esta agrupación nace desde un centro cultural del mismo nombre en la comuna de Santiago en 1987. Durante varios años sus quehaceres se dedicaron a la educación en talleres como cursos de alfabetización, de cultivo de diversas artes, de periodismo e historia, en conjunto con tener un papel activo en procesos de protesta y en ollas comunes.

Tras las consecuencias del terremoto de 2010, decidieron considerar la lucha por la vivienda como su elemento principal convirtiéndose en el Movimiento de Pobladores Ukamau. Desde entonces han orientado su accionar hacia la posibilidad de que las familias del sector aledaño al centro consigan una vivienda (Herrera, 2017). Lo anterior, se ha cristalizado en el proyecto Maestranza.

Al igual que en el caso del MPL, con Ukamau la lucha por el derecho a la ciudad no se concibe solamente como el obtener una vivienda. Su proyecto de buen vivir se entiende desde una lucha por el territorio (Herrera, 2017). En ese sentido, se propone una apropiación del barrio y la construcción de una comunidad. Los lazos sociales de su proyecto asumen como horizonte la vida sin delincuencia, drogas, violencia, ni individualismo.

El horizonte trazado se fundamenta en la autogestión como capacidad propia de los mismos pobladores de conseguir sus objetivos. Desde esa línea, se desprende en el caso del proyecto Maestranza, fueron los mismos vecinos quienes lograron a partir de un aprendizaje conformar los comités de vivienda, las personalidades jurídicas, postular y obtener los subsidios, negociaciones con el Servicio de Vivienda y Urbanismo (Serviu). Todo lo anterior, al interpretar como elemento prefigurativo discusiones y decisiones de manera horizontal, convierte a la comunidad en protagonista del proceso de construcción de ciudad.

La obtención de la vivienda como primer paso no deja que el Movimiento de Pobladores Ukamau no considere la importancia de la lucha contra las AFPs, el sistema de salud, el de transporte, entre otros 
factores, que configuran una desigualdad profunda en las ciudades chilenas, especialmente en Santiago de Chile (Herrera, 2017). Al mismo tiempo, contemplan su accionar como parte de una mayor conflictividad social en torno al modelo neoliberal.

El derecho a la ciudad y la vida digna se proponen de parte de ambas organizaciones desde una perspectiva más allá de la vivienda como objeto concreto separado de las otras instancias de la sociedad. La disputa por la construcción de vivienda busca construir también el entorno y la infraestructura barrial, factores que estaban ajenos en la política de vivienda social de los diferentes gobiernos (Herrera, 2017; Movimiento de Pobladores en Lucha, 2011). A la vez que la reivindicación habitacional busca ser parte de una lucha anticapitalista que integra otras demandas, como son pensiones dignas, un sistema de salud universal, educación pública y gratuita, entre otros elementos que han sido parte dela conflictividad social de los últimos años en el país.

El accionar de ambos grupos, refleja el quiebre de la escisión entre lo político y lo social. Durante los primeros años de democracia, en el país se vivió una verdadera desarticulación de los movimientos sociales, entre ellos, el de pobladores. Todo lo anterior significó la profundización del modelo de atomización social impuesto desde la dictadura militar. Las fracturas sociales que nacieron desde tomas como la de Peñalolén, o los movimientos estudiantiles, han traído como consecuencia la necesidad que sean los pobladores quienes se reapropien de las capacidades colectivas de decisión y de construcción del espacio urbano.

Por tanto, nos encontramos hacia una incipiente nueva disputa en torno a quienes son los actores que toman las decisiones respecto a la ciudad y la política urbana. La forma tradicional de los expertos se encuentra deslegitimada por quienes han sido marginados por las políticas de un Estado subsidiario que no garantiza derechos sociales. De cara al neoliberalismo que enfrenta a las personas entre sí y con el mundo, el accionar colectivo permite configurar a partir de la solidaridad nuevos lazos, toda vez que prefigura una sociedad diferente.

\section{Elementos en común y proyecciones}

Como se ha abordado en las secciones anteriores, las tres fuentes que hemos escogido para discutir la temática urbana y su transformación tienen como centro de su corpus la crítica a la estructuración urbana capitalista y al rol que el Estado ha tenido como facilitador del proceso de acumulación. Al mismo tiempo, la posibilidad de disponer de los medios prácticos para la construcción de una ciudad distinta, transformando la teoría en praxis.

Es por lo anterior que podemos mencionar seis aspectos esenciales de cruces entre estas perspectivas:

1. Reapropiación de la construcción de la ciudad: existe una disputa en torno a las capacidades materiales de reproducción del espacio urbano. Desde los conceptos situacionistas, su propuesta del urbanismo unitario, el derecho a la ciudad y el buen vivir del movimiento de pobladores existe una clara alusión a que el Estado y los privados son quienes poseen los medios y capacidades para la construcción de ciudad. En ese sentido, una reapropiación busca obtener dichas competencias y posibilidades.

2. La disputa se da en un plano de territorialización: en la misma línea que el elemento anterior, cuando hablamos de una disputa urbana estamos conceptualizando en torno al territorio. Es este en donde se encuentran las discrepancias políticas cuando el ejercicio de poder se conflictúa. Para poder lograr la transformación de la ciudad capitalista, la autonomía, autogestión y el accionar colectivo son elementos clave, pero no se entienden sin una territorialización del espacio urbano, un ejercicio que quiebre las alineaciones $y$ asimetrías espaciales.

3. La necesidad de superar el neoliberalismo y una perspectiva anticapitalista: el movimiento de pobladores se concibe como un foco de resistencia hacia los embates que el neoliberalismo ha traído a la sociedad chilena. Sin embargo, 
no se agota allí, entiende que el punto de nacimiento de una sociedad desigual se encuentra en el sistema capitalista y sus dinámicas depredadoras. Desde esa perspectiva, Lefebvre y la Internacional Situacionista pusieron el foco en la superación del capitalismo como piso mínimo para lograr un nuevo habitar. Ese proceso no debe esperar a la transformación total de la sociedad, sino que comienza desde el presente y tiene su nacimiento desde la vida cotidiana.

4. Más allá de la vivienda y la demanda hacia una nueva vida: ya hemos comentado que la vivienda no se concibe como mera necesidad aislada de otra, la cual puede ser satisfecha y, con ello, se finaliza la movilización. Nuestras fuentes de propuestas sobre una nueva ciudad nos incitan a pensar desde una visión de totalidad de la existencia en el medio urbano. Por tanto, lo que se encuentra en conflicto no es solamente algún elemento parcial de estas esferas fragmentadas. El centrarse en la vida misma busca precisamente orientar la acción hacia un conjunto de factores que permitirían un tipo de existencia no precarizada, con un claro sentido de comunidad.

5. Protagonistas del proceso: la finalización de las esferas separadas que el sistema capitalista posindustrial crea en forma de las imágenes de la participación requiere que sean los mismos habitantes de las ciudades quienes sean protagonistas del proceso. Es por esto por lo que movimientos como el MPL y Ukamau se presentan desde estas perspectivas. Frente a una institucionalidad que le es ajena, y muchas veces solo utiliza sus demandas para beneficiar a empresas, se plantean que sean los mismos pobladores los que gestionen todo el proceso. Claramente, existen aún ciertas limitantes en torno a controlar todo el proceso de planificación, ejecución de proyectos, pero se encuentra una clara línea de lo propuesto por Lefebvre en el derecho a la ciudad.
6. El urbanismo funciona como ideología: desde las teorizaciones de Lefebvre sobre las representaciones del espacio, la crítica del urbanismo de los situacionistas, encontramos la consolidación de una perspectiva que establece la existencia de un modo hegemónico de reproducción del espacio urbano que funciona a partir de la separación de quienes lo habitan en torno a su reproducción consciente. El espectáculo de la participación ciudadana es una ficción utilizada para crear la imagen de pertenencia e intervención. El movimiento de pobladores ha entendido dicha dimensión desde la perspectiva de la cooptación de la lucha. Aunque no se presente de manera explícita, busca romper con el ciclo ideológico al intentar controlar todo el proceso de producción de los complejos habitacionales. Sin una orientación hacia todo el proceso, la reducción a solo satisfacer demandas es un peligro. Allí donde se crítica el urbanismo de escritorio, se sobrepone como experiencia fundamental de la vivencia y transformación de la ciudad a la vida cotidiana y los espacios de representación.

\section{Conclusiones}

La discusión sobre el tema de este artículo es fundamental en un contexto de discusión a nivel institucional general sobre el derecho a la ciudad o el espacio urbano. En particular, en el caso chileno, en medio de la discusión de la propuesta de ley de Integración Social fuertemente criticada, pese a plantear la necesidad de que los proyectos consideren vivienda social y subsidios, continúa un modelo de gestión neoliberal en el que el Estado beneficia al privado, y los habitantes y pobladores del espacio siguen siendo incluidos sin una real participación.

El desborde de lo urbano requiere para su análisis perspectivas totales que integren una visión crítica de la producción y reproducción de este. En esa línea, la crítica al urbanismo como espectáculo en la planificación y construcción de la ciudad es una herramienta con la cual comenzar. La perspectiva 
del derecho a la ciudad se plantea como un llamado a la participación directa, no mediada, de los actores que viven en ella, sobrepasando la mera clasificación de clase, sin dejarla de lado, pero integrando todas las desigualdades y segregaciones existentes.

El movimiento de pobladores integra estas dimensiones y las amplía al considerarse no solo como un conjunto social agente de demandas en torno a la vivienda. Es la disputa del espacio y el territorio lo que se pone sobre la mesa. La vivienda se entiende como parte de un conjunto habitacional, con servicios que den satisfacción a derechos y necesidades en una perspectiva de vida plena. Por lo anterior, su proyección se encamina hacia una necesaria discusión y tensión con el urbanismo neoliberal chileno.

Más allá, la literatura revisada nos advierte de las posibilidades de coacción del derecho a la ciudad. Es posible mediante política social que el Estado logre satisfacer la necesidad de techo de los sectores más desfavorecidos. Sin embargo, el potencial transformador de su contenido requiere que quienes habitan el espacio urbano realmente tengan la capacidad de decisión sobre este. El urbanismo unitario se despliega como la ciudad al servicio de la vida humana y no la vida humana al servicio del urbanismo capitalista. Sin la necesaria prevención, demandas tan justas pueden terminar convirtiéndose en meros programas de ayuda.

Tampoco se debe olvidar que las perspectivas iniciada por Lefebvre y discutidas por el situacionismo inauguran una óptica desde la cual la lucha en el espacio urbano no es considerada como un fin en sí mismo. Es un proceso, un paso, necesario, que debe estar encausado en la superación de una sociedad que pone en primacía el valor de cambio sobre el valor de uso, a la vez que aliena separando a las personas de los medios de su subsistencia y habitar.

\section{Referencias}

Angelcos, N. (2012). Lucha por la vivienda y politización de las trayectorias individuales. Polis. Revista Latinoamericana, 11(31), 17-38. https://polis.revues. org/3593
Carlos A. F. (2014). La ciudad como privación y la reapropiación de lo urbano como ejercicio de la ciudadanía. Scripta Nova. Revista Electrónica de Geografía y Ciencias Sociales, 18. http://revistes.ub.edu/index. $\mathrm{php} /$ ScriptaNova/article/view/14979

Carlos, A. F. (2015). El "derecho a la ciudad" como pensamiento-acción. En C. De Mattos y F. Link (eds.) Lefebvre revisitado: capitalismo, vida cotidiana y el derecho a la ciudad (pp. 233-252). RiL editores.

Constant. (2001). Otra ciudad para otra vida. En Internacional Situacionista textos completos en castellano de la revista Internationale Situationniste (1958-1969). Vol. 1. La realización del arte (pp. 106-110). Literatura Gris.

Cortés, A. (2014). El movimiento de pobladores chilenos y la población La Victoria: ejemplaridad, movimientos sociales y el derecho a la ciudad. EURE: Revista de Estudios Urbanos Regionales, 40(119), 239-260. http:// dx.doi.org/10.4067/S0250-71612014000100011

Debord, G. (1994). La sociedad del espectáculo. Ediciones Naufragio.

Debord, G. (2000). Introducción a una crítica de la geografía urbana. A Parte Rei: revista de filosofía, (11). https:// dialnet.unirioja.es/servlet/articulo? codigo $=3887677$

Debord, G. (2001a). Posiciones situacionistas sobre la circulación. En Internacional Situacionista textos completos en castellano de la revista Internationale Situationniste (1958-1969). Vol. 1. La realización del arte (pp. 105-106). Literatura Gris.

Debord, G. (2001b). Teoría de la Deriva. En Internacional Situacionista textos completos en castellano de la revista Internationale Situationniste (19581969). Vol. 1. La realización del arte (pp. 55-57). Literatura Gris.

Harvey, D. (1990). Los límites del capitalismo y la teoría marxista. Fondo de Cultura Económica.

Harvey, D. (2004). El "nuevo" imperialismo: acumulación por desposesión. Socialist Register, 40. http:// biblioteca.clacso.edu.ar/gsdl/collect/clacso/index/ assoc/D8555.dir/harvey.pdf

Harvey, D. (2013). Ciudades rebeldes. Del derecho a la ciudad a la revolución urbana. Akal.

Herrera, J. (2017). El Movimiento de Pobladores UKAMAU. Capital social comunitario y lo político en el nuevo movimiento de pobladores en Chile. [Tesis de grado, Universidad de Chile]. Repositorio institucional UChile http://repositorio.uchile.cl/ handle/2250/152332 
Herrera, J. (2018). El nuevo movimiento de pobladores en Chile: el movimiento social desplazado. Polis, Revista Latinoamericana, 19(49), 177-199.

Internacional Situacionista. (2001). Critica del Urbanismo. En Internacional Situacionista textos completos en castellano de la revista Internationale Situationniste (1958-1969). Vol. 1. La realización del arte (pp. 199-206). Literatura Gris.

Ivain, G. (2006). Formulario para un nuevo urbanismo. En Internacional Situacionista, Urbanismo Situacionista (pp. 6-21). Gustavo Gili.

Jappe, A. (1998). Guy Debord. Anagrama.

Kotanyi, A. y Vaneigem, R. (2006). Programa elemental de la Oficina de urbanismo unitario. En Internacional Situacionista, Urbanismo Situacionista (pp. 22-31). Gustavo Gili.

Lefebvre, H. (1968). El Derecho a la Ciudad. Ediciones Península.

Lefebvre, H. (2013). La Producción del Espacio. Capital Swing.

Marx, K. y Engels, F. (1974). La Ideología Alemana. Crítica de la novísima filosofía alemana en las personas de sus representantes: Feuerbach, B. Bauer y Stirner y del socialismo alemán en las de sus diferentes profetas. Ediciones Pueblos Unidos.
Molano, F. (2016). El derecho a la ciudad: de Henri Lefebvre a los análisis sobre la ciudad capitalista contemporánea. Folios, (44), 3-19. https://doi. org/10.17227/01234870.44folios3.19

Movimiento de Pobladores en Lucha. (2011). 7 y 4 el retorno de los pobladores. Lucha por la vivienda, autogestión habitacional y poder popular en Santiago de Chile. Quimantú.

Santos, M. (1996). De la totalidad al lugar. Oikos-Tau.

Santos, M. (2007). Técnica, espaço, tempo. Edusp.

Santos, M. (2009). Por uma economia política da cidade. O caso de São Paulo. Edusp.

Soja, E. (2008). Posmetrópolis, estudios críticos sobre las ciudades y las regiones. Traficantes de Sueños.

Soja, E. (1996). Third Space. Journeys to Los Angeles and Other Real-and-Imagined Places. Blackwell Publishers Inc.

Vaneigem, R. (2001). Comentarios contra el urbanismo. En Internacional Situacionista textos completos en castellano de la revista Internationale Situationniste (1958-1969). Vol. 1. La realización del arte (pp. 228232). Literatura Gris. 
